\title{
Public Welfare vs Business - the Future of Tax Premium Health Insurance
}

\author{
Hongmin Sun \\ Zhongnan University of Economics and Law \\ Wuhan, China 430073
}

\begin{abstract}
The tax premium health insurance has been put into operation and promoted in China since 2016, yet the overall effect is not satisfying enough, with some improvement, though. Through in-depth analysis of its development status, origin and types and comprehensive analysis of operational problems of tax, this paper discusses the future development of the tax premium health insurance from a broad perspective. Finally, the paper proposes that the government and enterprises must, on the premise of rationally distinguishing the public interest and commercial standpoint of tax premium health insurance, promote the development of tax premium health insurance by establishing a coordination and communication mechanism, improving the construction of relevant systems, strengthening the construction of information system, broadening the coverage group of tax premium health insurance, and improving the self-mechanism of the insurance type.
\end{abstract} future

Keywords-tax premium health insurance; development;

\section{INTRODUCTION}

On March 4, 2016, the tax premium health insurance accepted its first insurance in China. ${ }^{1}$ By March 2017, in the first annual cycle of operation, the business accumulated 63,000 effective insurance policies with about 108 million yuan of premiums in reality. This type of insurance was introduced nationwide on July 1, 2017. By April 2018, in the second annual cycle of operation, the business had about 158,000 effective insurance policies with paid-up premiums of about 526 million yuan accumulated.

It can be seen from the data that after the pilot was extended to the whole country, both the number of insurance policies and the paid-in premium increased significantly compared with the previous annual cycle. However, in terms of absolute number, the cumulative number of effective insurance policies since the establishment of this business, which is 221,000 (without considering renewal of insurance policies), is too small compared with the number of taxpayers in China ${ }^{2}$, with the number of buyers accounting for less than $0.4 \%$ of the number of taxpayers. In terms of premiums, China's insurance industry earned 438.9 billion yuan in health insurance premiums in 2017, among which

\footnotetext{
Data source: Commercial Health Insurance Information Platform According to comprehensive data from all aspects in China, the total number of taxpayers in 2017 is estimated at 70 million.
}

the premium of tax premium health insurance accounted for less than $0.15 \%$. What problems have occurred in the development of tax premium health insurance? What is the future of tax-free health insurance?

\section{CharaCtERISTICS OF TAX PREMIUM HEALTH INSURANCE}

\section{A. Definition of Tax Premium Health Insurance}

The tax premium health insurance mentioned in this paper refers to the specific personal health insurance products that can be deducted from personal income tax and have been approved by the CIRC on file launched by commercial insurance companies which meet the requirements of CIRC for examination and approval of business tax premium health insurance under the guidance of the relevant documents on it.

\section{B. Advantages of Tax Premium Health Insurance}

Tax premium health insurance products have special advantages since their birth because of their special positioning and nature. This paper will focus on the tax premium health insurance products themselves and their advantages compared with traditional health insurance products.

1) Exclusive advantage: Supported by national policy, they can deduct income tax and enjoy unique balance refund mechanism

Tax premium health insurance policy holders can enjoy preferential policies for individual tax, which is the unique advantage of this product. According to the current provisions of the relevant documents on preferential tax, individuals who meet the requirements for purchasing preferential health insurance products can enjoy the pre-tax deduction of up to 2400 yuan/year. According to China's calculation standard for personal income tax in 2018, individual taxpayers can enjoy a maximum of 1,080 yuan per year of personal income tax reduction or exemption.

Tax premium health insurance products are operated in the form of universal insurance, which is divided into medical insurance accounts and personal accounts. According to relevant documents, the simple loss rate of the 
tax premium health insurance shall not be lower than $80 \%{ }^{3}$. If the actual loss rate is lower than $80 \%$, the insurer shall return the difference to all the insured's personal accounts. Such regulation limits the underwriting profits of insurance companies and urges insurers to strengthen compensation management so as to ensure the insured's insurance interests.

2) Underwriting advantage: free transfer of policy rights and interests, high security of account rights and interests

According to the relevant provisions of the tax premium health insurance, the insured can transfer the policy to another insurance company free of charge after the end of the individual medical expense risk protection liability period; the insurer shall not demand the insured to change the insurance company by force or in a disguised way. In the case of policy transfer of the insured, he insurance company shall not set the hesitation period, but are allowed to underwrite the policy.

Tax premium health insurance products are operated in the form of universal insurance, which is divided into medical insurance accounts and personal accounts. After deducting the cost of the basic medical insurance account, the entire premium paid by individuals each year will enter the individual universal account, and the interest is calculated in the way of compound interest according to the universal insurance interest rate, with a minimum guaranteed annual interest rate as $2.5 \%$.

3) Underwriting advantage: acceptance of insurance with diseases

Underwriting is a key part of insurance acceptance. For traditional health insurance products, in the process of underwriting, the insurance is usually refused or excluded due to the anamnesis of the insured. However, as a special type of insurance, the tax premium health insurance clearly stipulates that the insurance shall not be refused, that is to say, the insurance shall be accepted with illness (but the sum insured has been reduced). This regulation breaks through the general rules of traditional commercial health insurance and provides a channel for sub-healthy groups to purchase health insurance.

4) Security advantage: high insurance coverage, high reimbursement ratio, and wide range

Compared with traditional health insurance products, it is stipulated that the annual insurance amount of medical insurance in the tax premium health insurance shall not be less than RMB 200,000 yuan, and the accumulative reimbursement limit shall not be less than RMB 800,000 yuan (the sum insured is slightly reduced for the first time for the unhealthy groups with illness), with relatively a high insurance coverage.

At the same time, it is stipulated that expense of insurant occurrence within the range of the social security catalogue are $100 \%$ reimbursed, and the expenses outside the social

Simple loss ratio $=$ (all claims incurred during the life of the policy for that fiscal year + additional costs for that fiscal year)/(all premiums paid for policies in force for that fiscal year) $* 100 \%$ security catalogue are $80 \%$ reimbursed. At the same time, the overall out-of-pocket proportion of insurant's medical expenses in accordance with the insurance contract shall not be higher than $10 \%$, that is, the proportion of individual overall compensation reaches $90 \%$, so the reimbursement ratio is relatively high.

In addition, a clear agreement has also been made on the scope of reimbursement of tax premium health insurance. Insurance liability including four sections: hospitalization expenses insurance; insurance for outpatient expenses before and after hospitalization; outpatient treatment expense insurance for chronic diseases; insurance for specific outpatient treatment costs. In practice, some insurance companies increase and broaden the liability of basic insurance. Therefore, compared with conventional health insurance products, the insurance coverage is wide.

5) Claim advantage: no absolute deductibles and no waiting period

In order to improve the efficiency of claim settlement and reduce the loss of claim settlement, traditional health insurance usually sets certain absolute deductibles for single accident or annual accident. However, there is no absolute deductible in the tax premium health insurance, that is, the absolute deductible is zero.

Similarly, traditional health insurance usually has a waiting period (ranging from 30 days to 18 days) after the contract takes effect, while tax premium health insurance has a no waiting period. That is, as long as the contract is successfully purchased, the patient can also be compensated for illness on the day the contract takes effect.

\section{6) Renewal advantage: renewal security}

Explicit provisions on guarantee renewal are made in tax premium health insurance. Declinature increase of fee will not occur in the renewal of insurance due to claims during the effective period of the previous insurance policy. Similarly, for the population who is insured for the first time as healthy people and then become sub-healthy in the case of illness, the calculation of the total insured amount is still based on the condition of them when they first insured, and does not decrease due to changes in personal circumstances.

\section{Challenges of Tax Premium Health Insurance}

Although the tax premium health insurance has many advantages, there are still many challenges in its development. The following part mainly analyzes the challenges faced by the tax premium health insurance from the internal and external challenge factors.

\section{1) Internal factors of challenge}

The internal factors of challenge facing tax premium health insurance mainly come from its own, including its special background, product problems and from other aspects.

In terms of its special background, the policy dividend promotes the birth of the insurance. However, there are certain positions and interests that are more or less inconsistent between the government that sets policy and the 
insurance companies that develop and operate the products, which will bring challenges to the development of insurance products. At the same time, as an insurance put into promotion just from pilot, the product is faced by a lot of challenges in that its guiding policy and other aspects also have much to be improved under the complex and changeable market environment.

From the point of view of the product itself, the main problems it faces are the controversial points and its internal factors to be improved.

\section{2) External factors of challenge}

First, challenge from market is mainly the impact of new products in the market. With the improvement of residents' income level and education level, people's insurance awareness is increasing. At the same time, in recent years, due to environmental damage, life pressure and other factors leading to more and more diseases, the public pay more and more attention to health insurance. Against this background, the major insurance companies have developed many new health insurance products. These new products have similar functions to the tax premium health insurance. Although there is no preferential tax policy for them, they have advantages in insurance rate, insurance liability, insurance amount and other aspects. So, the emergence of these new insurance products has hindered the promotion and development of tax premium health insurance products.

Secondly, the challenge comes from the product operators, namely the insurance companies. According to the provisions of the measures for the administration of tax premium health insurance business, there are specific access requirements for their solvency, business departments and staffing for insurance companies operating tax preferred health insurance. The restriction of business access conditions provides a guarantee for the operation of this insurance, but at the same time, the high access threshold restricts most operators, which will bring corresponding challenges to the development of tax premium health insurance.

\section{The MaIn PRoblems IN THE OPERATION OF TAX PREMIUM HEALTH INSURANCE}

From the development status of tax premium health insurance, the trial implementation and promotion of insurance varieties have some breakthroughs, but the overall effect is not good enough. The main problems found in the operation of tax premium health insurance are as follows.

\section{A. Policy: Intensity of Tax Preference}

Tax preference is the most important feature of tax premium health insurance. According to the preferential tax policy, taxpayers can enjoy a tax credit of 2,400 yuan per person per year. According to China's 2018 personal income tax calculation standards, individuals with pre-tax income of more than 80,000 yuan per month and 960,000 yuan per year can enjoy a tax cut of up to 1,080 yuan per year. According to the tax-saving effect, the taxpayer's maximum monthly tax payment accounts for $13.33 \%$ of the tax amount, and the lowest is less than $0.31 \%$. According to the maximum percentage of saved tax in income, the monthly income of the saved tax is up to $0.32 \%$, and the lowest is less than $0.08 \%$, which is very small. The intensity of tax incentives to taxpayers is of very little attraction, coupled with the complex insurance process currently and other reasons may further reduce the enthusiasm of policyholders.

\section{B. Participants: the Participants Fail to Take Unified Actions}

1) Government: no good communication mechanism has been established between departments

The government is in the leading position in the promotion of tax premium health insurance. Government departments have formulated relevant policies and a series of guidelines for products. However, because the government has no previous experience in the operation of relevant products, the actual guiding rules are being improved while promoting. Moreover, the whole product promotion and operation process involves many government departments, yet a good communication mechanism has not been established, so the overall promotion is not good enough.

2) Insurance company: caution in product promotion

As a policy product, the tax premium health insurance product is has a certain public welfare nature since its birth. But this product is actually operated by non-public insurance companies. As a policy-based product with a public welfare nature, it has the following features: "allowing insurance with disease", "no waiting period", "no deductibles" and "refund of the balance", which fully reflect the nature of public welfare. However, some of them are in conflict with the insurance principles and interests of commercial insurance companies, which brings some difficulties to insurance companies in risk selection, business operation and business management, and in particular, it sets an upper limit on the profit space of insurance companies. For a newly listed insurance product with large promoting cost, blank operation experience and uncertain profit prospect, insurance companies are cautious in promoting it.

\section{3) Marketer: low marketing enthusiasm}

The main sales channels of tax premium health insurance products are insurance salesmen, especially group marketing staff and comprehensive development personnel. However, the commission ratio of the product is very small compared with the commission ratio of the products sold by these marketers on a daily basis, while the workload of sales and service is larger than that of the products sold on a daily basis. At the same time, the insurance company has not made clear the specific assessment policies on whether the product is included in the assessment of marketing staff and how to assess it, so the enthusiasm of marketing staff is low.

\section{4) Customer: limited direct customer group}

The policy stipulates that the customers of tax premium health insurance products shall be tax payers. In practice, the tax payer is defined as the individual income tax payer of the previous year. However, China is a country mainly collecting taxes indirectly, and the proportion of direct tax payers is low. Before the new individual income tax law was adjusted, the proportion of tax payers in the working 
population was still less than $10 \%$ in 2017 according to China's 2011 personal income tax standards. The proportion of tax payers is small, and the direct customer groups have certain limitations.

\section{The Product Itself: the Insurance Has Its Own Defects}

\section{1) Short guarantee period}

Tax premium health insurance products are one-year insurance products, whose purchase and protection are based on the premise of "tax payment". Although most of the tax premium health insurance products can be extended to the time after retirement, there is no significant breakthrough in the actual age of expansion. The stage after retirement is the most in need of medical security, so there is a certain gap between the product and the actual needs of the masses.

\section{2) Lack of core competitiveness of the product}

The basic positioning of tax premium health insurance product is to supplement the basic medical insurance products. However, in terms of its insurance liability, it has many overlapping parts with the basic medical insurance liability of urban workers and the supplementary medical insurance liability of enterprises, leading to its lack of core competitiveness.

\section{3) Universal risks cannot be used to funds withdraw} funds

In the operation of tax premium health insurance, the regulatory authorities clearly stipulated that the minimum payment per person should be 2,400 yuan per year, and the premium higher than the personal risk guarantee should be credited to the personal universal insurance account. However, the universal insurance account can only be used for the purchase of commercial health insurance and personal medical expenses after retirement, and cannot be withdrawn or used for other purposes.

\section{Product Operation: the Process of Insuring Is Complex}

Because the tax premium health insurance features tax premium, there are an additional procedure for tax premium compared with traditional insurance. In the early stages of insurance promotion, the operation requires the cooperation of multiple departments. Yet without not a sound information system and a good communication mechanism, operators at all levels are groping, thus the whole insurance process is complex and needs a long cycle.

\section{E. Market: Insufficient Publicity and Promotion, Market Crowding-out Effect}

As a policy-based commercial insurance product, tax premium health insurance features tax preference and insurance guarantee. However, in practice, due to various reasons, its promotion efforts are not enough, and many people do not know about the product. At the same time, the function of this product overlaps with some commercial insurance of insurance companies, so it will there might be crowding-out effect, which will affect the benefits and profits of insurance companies. Therefore, the sales enthusiasm of insurance companies is not high, and the overall market operation is not ideal.

\section{DISCUSSION ON THE FUTURE IMPROVEMENT SPACE OF TAX PREMIUM HEALTH INSURANCE}

Based on the development status, background, characteristics and operation of the tax premium health insurance, the author holds that there is a broad space for its future development. As a commercial insurance product for public welfare, its development depends on the joint efforts of the government and insurance companies. In the following part, the future improvement space of tax premium health insurance is discussed from the perspectives of the government, the insurance company, the joint efforts of insurance company and the government, and the product itself.

\section{A. National Policy}

\section{1) Increasing Tax Preference}

At present, preferential tax policies are less powerful and less attractive to taxpayers. Considering the increase of tax threshold, if the policy remains unchanged, the actual preferential tax intensity will be less. It is suggested that the state should increase the tax preference according to the actual income of residents so as to realize the tax preference characteristics of tax premium health insurance products.

2) Clarifying and improving the details of the tax premium health insurance policy

At present, there are still many details to be clarified and improved in the policy of tax premium health insurance. Taking the profit balance refund mechanism of insurance company for example, at present, according to the policy, the balance shall be returned to all insured accounts, but the specific implementation details need to be clarified. In addition, the return to all insured accounts does not reflect the fairness principle of insurance, which may lead to repeated profits for the people who claim compensation, but is unfair to the people who do not, so there is also a large space for improvement.

\section{3) Increasing support for insurance companies}

In addition to the characteristic of tax preference, the tax premium health insurance also makes certain breakthrough in underwriting rules, etc., like allowing insurance with diseases and balance return, etc. all bringing certain difficulty to the insurance company's management. Therefore in the actual implementation, insurance companies have to worry a lot. It is suggested that the government should increase its support to insurance companies, provide policy support related to the types of tax premium health insurance for insurance companies, and fully enhance the enthusiasm of insurance companies to operate tax premium health insurance products.

4) Further clarifying and refining regulatory standards to strengthen market behavior supervision

The regulators of tax and health insurance should further clarify and refine the regulatory standards to strengthen the management of market behavior. Efforts should be made to formulate a sound entry and exit mechanism and improve punishment standards for violations of laws and regulations, so as to ensure market order and the rights of the insured 
5) Formulating the unified social security catalogue of the industry

At present, there are two manifestations of the reimbursement list out of the range of social insurance for tax premium health insurance in the market. One is a "positive list", that is, a catalogue where the part that can be reimbursed is clearly stipulated. Namely, only the scope of listed liability can be reimbursed. The other is the "negative list", that is, the catalogue where the part outside the range of social insurance which cannot be reimbursed is listed. Namely, reimbursement is approved in any case except for the scope with listed liability. Yet for the majority of consumers, their level of professional knowledge is generally not high. So there might be misunderstandings and thus disputes, which will not only affect consumers' impression of tax premium health insurance products, but also affect their rights and interests. It is suggested to formulate a unified social security catalogue in the industry from the regulatory level.

\section{B. Insurance Company}

\section{1) Clarifying the responsibilities}

The actual operator of tax premium health insurance is the insurance company. There are also different divisions of labor and different levels within the insurance company, and there are some conflicts of interest within the insurance company. In order to promote the tax premium health insurance, the internal insurance company must clearly define the responsibility and determine the specific responsibility departments, responsible persons and relevant interests. And the top-down responsibility and accountability mechanism should be formulated for the promotion of the insurance. Only with clear responsibility and ownership of rights and interests, the promotion of insurance can be better.

\section{2) Standard operation guidance}

In the practical operation of tax premium health insurance, it will inevitably encounter various problems. Insurance companies should do a good job in pre-, post-, and post-event periods in the standard operation guidance of tax premium health insurance. It is necessary for them to make reasonable and standardized publicity in advance, reasonably predict problems, and take preventive measures in advance; timely feedback should be given to solve problems in the process; and carefully summary and reflections should be made afterwards. In this way standard and perfect operation guidance can finally be formed.

\section{3) Optimizing operation flow}

A major difficulty in the promotion of tax premium health insurance is the complex business process, including filling in the application form, obtaining tax reduction and exemption, etc., in which there is much waste of manpower and material resources

\section{4) Making innovation in marketing mode}

At present, most of the sales business of tax premium health insurance comes from group direct selling and comprehensive development, while the sales channels of agency, broker and Internet are used less. With the development of science and technology and the improvement of channels, the impact of the marketing model on cost and scale is huge. In the future, insurance companies should make innovation in marketing models and vigorously develop online sales and brokerage agency business, especially the online sales business relying on new technology.

\section{5) Enriching product system}

Tax premium health insurance is a product developed and operated under the guidance of national policies. However, the functions of tax premium health insurance are limited, which cannot meet the diversified insurance needs of people. In practical operation, insurance companies can combine the original insurance products or the development of new products with tax premium health insurance as optional products to form a new product system and sell them together, so as to meet the needs of customers of different levels and categories.

\section{6) Improving service quality}

With the continuous improvement of people's living standards, people's insurance needs gradually increase. At the same time, the people's requirements for the quality of insurance services have been gradually improved. Therefore, in order to promote the long-term and stable sales of products, insurance companies must improve the service quality, so that the excellent service quality can escort the promotion of tax premium health insurance.

\section{7) Strengthening risk prevention and optimizing claims} control

As an insurance product for public welfare, there are some breakthroughs in tax premium health insurance compared with traditional insurance in many aspects, which brings some risks to the actual operation of the product. Therefore, risk prevention and claim control are of vital importance for the long-term and steady promotion of tax premium health insurance. Through making full use of their own advantages, insurance companies should on the one hand strengthen cooperation with health consulting companies, and on the other hand, further integrate medical resources, strengthen cooperation with relevant medical institutions, and deeply control claims. At the same time, they should further improve their own claims and other related personnel comprehensive quality level, multi-linkage, so as to further strengthen risk prevention, optimize claims control.

\section{Joint Efforts of the Government and Insurance Company}

\section{1) Strengthening the publicity}

The banking and insurance regulatory department, relevant fiscal and tax departments, insurance industry organizations and insurance companies should jointly carry out multi-channel and diversified publicity activities, so as to let more people understand and recognize tax-advantaged health insurance, and thus promote the development of taxpremium health insurance business

\section{2) Establishing business information platform}

Based on the complexity of tax premium health insurance products and the complexity of individual income tax 
exemption and reduction, it is very important to establish a business information platform. The banking and insurance regulatory department, relevant fiscal and tax departments, insurance industry organizations and insurance companies should jointly establish business information platform to realize the rapid circulation of information and the rapid handling of business, and realize the functions of quick insurance, quick tax preference handling, quick policy inquiry and quick claim service, etc.

\section{3) Establishing communication and coordination} mechanism

The introduction and operation of tax premium health insurance products involve many departments from the government to enterprises. Therefore, effective communication and coordination mechanism must be established to achieve successful and efficient operation of products. Relevant responsible persons of each department shall establish a daily communication platform and hold regular communication and exchange meetings, and establish a communication and coordination mechanism to deal with all kinds of unexpected problems, optimize business processes, and improve business efficiency, so as to promote the smooth operation of tax preferential health insurance.

\section{Product Improvement}

\section{1) Further refining the terms}

There are parts of the tax premium health insurance clause that need to be improved. For example, the use of universal insurance and the difference compensation mechanism and so on all need improvement. Meanwhile, as a supplementary public welfare product, it needs to update its function synchronously with the social insurance in the reform.

\section{2) Attempting to increase the insurance coverage}

At present, the insurance coverage of tax premium health insurance is lower than that of the functionally homogeneous products in the market. So it is advisable to try to increase the insurance amount of tax premium health insurance according to the claim status in the actual operation, especially the insurance coverage of those who can get an advantage for anamnesis in their policies.

\section{3) Reasonably regulating the renewal period}

Because the tax premium health insurance is directly related to individual income tax at the beginning of its birth, taxpayers are not eligible to buy it after they retire without paying taxes. Based on this limitation, the insurance company has broadened the product renewal cycle to a certain extent, and stipulated that the insured's renewal can be extended to a certain age. But according to the implementation at present, regulations of each insurance company are all inconsistent, and there are generally not many years extended. Therefore, the tax premium health insurance should make a certain standard for the renewal period.

\section{4) Broadening the liability}

Currently, there are two kinds of account functions, namely medical insurance account and universal personal account. The insurance liability of the medical insurance account mainly covers hospitalization, outpatient service before and after hospitalization, outpatient service for chronic diseases and specific outpatient service. In practice, insurance companies make different provisions for insurance products with different terms according to the insurance liability within the scope of guidance, especially for chronic diseases and treatment for specific outpatient clinics. In the later stage, the insurance liability can be appropriately expanded according to the settlement of claims in the early stage, such as expanding the scope of chronic diseases and specific outpatient service, and appropriately considering increasing the general outpatient service with certain scope and certain amount.

\section{5) Expanding the range of insurance coverage target}

At present, the target of tax premium health insurance is the individual tax payer. But the actual number of taxpayers in China is small. Therefore, the number of direct customers of the insurance is small, which is not in line with the original intention of the product as a public welfare product, and is not conducive to the risk diversification of insurance. In the promotion of future products, all people who are likely to pay personal income tax may be considered as the direct target. Meanwhile, the spouse and children of the direct target may also be considered to be included in the coverage, so as to better expand the range of the insured. Although some people cannot actually enjoy tax incentives when buying products, this product provides them with a better choice of insurance products, which is conducive to the overall promotion and risk diversification of this product.

\section{CONCLUSION}

The tax premium health insurance bears the responsibility of alleviating and solving the problem of "difficulty and high expense of medical service" for Chinese people and building a healthy China. So its large-scale promotion and long-term stable development are necessary. However, there is much to be improved in the insurance type itself. First of all, the subjects involved in the insurance industry must clarify the positioning of their public goods and commercial products, and return to the public goods mentality and marketization operation from the perspective of concept. Second, the government and insurance companies should increase publicity, increase the intensity of tax preference, improve policies, standardize operations, integrate resources, coordinate interests, straighten out relations, be bold to make innovations and cooperate with each other. Only with the joint efforts of all parties, can the tax premium health insurance enjoy a healthy and rapid development and truly fulfill its original intention of "benefiting the country, and solving the difficulties of the people".

\section{REFERENCES}

[1] Opinions of the state council on Accelerating the Development of Modern Insurance Service Industry [J]. Shanghai Insurance, 2014(11) 5-8. (in Chinese) 
[2] Ma Xiangdong. A Study on the Trend of Tax-preferred Health Insurance in China [J]. Journal of Insurance professional College, 2017, 31(06): 21-24. (in Chinese)

[3] Zhu Minglai, Wan Yu. Reflections on improving tax preferential policies for health insurance [J]. China Health Insurance, 2017, (08): 65-68. (in Chinese)

[4] Feng Pengcheng. Discussion on the pilot implementation and improvement of personal tax premium health insurance in China [J]. China Health Insurance, 2017(06): 62-67. (in Chinese)

[5] Bian Shaogian, Zhao Qian, Liu Yongzhong. SWOT analysis on the development of tax premium health insurance [J]. China Business \& Trade, 2017(21): 19-20. (in Chinese)

[6] Wei Xiaotong. Policy Suggestions on improving tax premium health insurance in China [J]. Tax Paying, 2018(06): 187. (in Chinese) 